\title{
DIREITO SUCESSÓRIO: DOS DIREITOS HEREDITÁRIOS DO CÔNJUGE
}

\author{
Graciela Fernandes Thisen ${ }^{1}$
}

\section{DO DIREITO SUCESSÓRIO}

O direito das sucessões surge na antiguidade com fortes ligações na "ideia de continuidade da religião e da família”. ${ }^{2}$ Conforme os ensinamentos de Carlos Silveira Noronha:

[...] originariamente, em tempos pré-clássicos anteriores à Grécia e à Roma, segundo afirmam os historiadores, não se cogitou da transmissão patrimonial do antecessor para o sucessor pela via sucessória mortis causa porque a titularidade do direito de propriedade que constitui o objeto do direito sucessório não era atribuído ao indivíduo em particular, mas ao chefe da tribo, do grupo ou do clã a que estivesse submetido. Deste modo a morte de uma pessoa integrante dessas coletividades não alterava o status jurídico da propriedade. ${ }^{3}$

Posteriormente, com o caráter "familiae da propriedade, desenvolveu-se a ideia de continuação (su-

1 Graduada em Direito pela Universidade de Santa Cruz do Sul. Especialista e mestre pela Pontifícia Universidade Católica do Rio Grande do Sul. Especialista em Gestão Educacional pelo Serviço Nacional de Aprendizagem Comercial. Atualmente, é coordenadora do curso de Direito das Faculdades Integradas São Judas Tadeu, membro da Comissão de Ensino Jurídico da Ordem dos Advogados do Brasil - Seccional do Rio Grande do Sul - OAB/RS, avaliadora da Educação Superior dos cursos de Direito do INEP/MEC e advogada.

2 GONÇALVES, Carlos Roberto. Direito civil brasileiro: direito das sucessões. v. 7. 4. ed. São Paulo: Saraiva, 2010, p. 21.

3 NORONHA, Carlos Silveira. Reflexões doutrinárias acerca do Direito das Sucessões. In: NORONHA, Carlos Silveira (Org.). As novas perspectivas do direito das sucessões em tempos de modernidade e pós-modernidade. Porto Alegre: Sulina, 2011, p. 9. 
cessão) de novo chefe de grupo nos bens que se achavam sob a direção do chefe premorto". ${ }^{4}$ A respeito do tema, convém descrever os ensinamentos de Caio Mário da Silva Pereira:

A ideia de sucessão somente veio a ganhar corpo com a propriedade individual. [...] A concepção religiosa exigia que tivesse o defunto um continuador de seu culto, que lhe fizesse os sacrifícios propiciatórios, e lhe oferecesse o banquete fúnebre. Antes, pois, de ser econômico, o fundamento da sucessão por causa de morte foi religioso: os bens transmitiam-se do defunto ao herdeiro como instrumento propiciatório aos deuses domésticos, e bem assim como meio de continuar na descendência a religião dos antepassados. A unidade da família e a autoridade do seu chefe concorrem, de um lado, na transmissão de pleno direito e, de outro, na criação do testamento. Depois, desenvolveuse no outro sentido, ligado à continuação da vida que sugere a continuidade patrimonial. [...] Em Roma, a morte do pater famílias autorizava os herdeiros a recolher a sucessão, mas igualmente era lícito indicar o defunto os seus sucessores. ${ }^{5}$

Assim, com o passar do tempo e sob a influência social, política e econômica, "a conservação e transferência hereditária interessa ao mesmo tempo ao indivíduo e à sociedade". ${ }^{6}$ Dessa forma, hodiernamente, conforme refere Washington de Barros Monteiro:

[...] o direito das sucessões baseiase ainda na importante função social que desempenha, conservando unidades econômicas a serviço do bem comum. Operaria, sem dúvida, improdutivo dispêndio de energias, se essas unidades devessem desaparecer pela morte das pessoas que as criaram e as mantiveram, impondolhes a restauração por outros homens. A sociedade tem por isso o maior interesse na subsistência da herança, porque, com a sucessão, sobrevivem tais unidades, sem solução de continuidade, em benefício geral. ${ }^{7}$

O termo "sucessão", de origem latina successio, derivado de suce-

4 PEREIRA, Caio Mário da Silva. Instituições de direito civil. 12. ed. v. 6. Rio de Janeiro: Forense, 2005, p. 4-5.

5 PEREIRA, Caio Mário da Silva. Instituições de direito civil. 12. ed. v. 6. Rio de Janeiro: Forense, 2005, p. 5.

6 PEREIRA, Caio Mário da Silva. Instituições de direito civil. 12. ed. v. 6. Rio de Janeiro: Forense, 2005, p. 5.

7 MONTEIRO, Washington de Barros. Curso de direito civil. 30. ed. v. 6. São Paulo: Saraiva, 1995, p. 9. 
dere $^{8}$, significa uns após os outros, ou seja, "sempre que uma pessoa tomar o lugar de outra em uma relação jurídica". ${ }^{9}$ A sucessão na acepção da palavra significa "o ato pelo qual uma pessoa assume o lugar de outra, substituindo-a na titularidade de determinados bens". ${ }^{10}$

$\mathrm{O}$ direito das sucessões significa no sentido objetivo um "conjunto de normas e de princípios destinados a regular a transmissão de direitos e de obrigações deixados por alguém que morre”, já no sentido subjetivo "respeita à posição jurídica de uma pessoa que é herdeira ou legatária daquela que morreu". ${ }^{11}$

A sucessão ${ }^{12}$ poderá ocorrer de duas maneiras, quais sejam "por vontade das partes ou em razão da morte. Se decor-

8 Termo sucedere "tem o sentido genérico de virem os fatos e fenômenos jurídicos 'uns depois dos outros' (sub + cedere). Sucessão é a respectiva sequência” (PEREIRA, Caio Mário da Silva. Instituições de direito civil. 12. ed. v. 6. Rio de Janeiro: Forense, 2005, p. 1.). Segundo Silvio Rodrigues, "A ideia de sucessão sugere, genericamente, a de transmissão de bens, pois implica a existência de um adquirente de valores, que substitui o antigo titular" (RODRIGUES, Silvio. Direito civil: direito das sucessões. v. 7. 21 ed. São Paulo: Saraiva, 1997, p. 03). Para Pontes de Miranda, "quem sucede põe-se no lugar da pessoa de quem provém o patrimônio ou o direito ou de quem provém alguns direitos. Sucede-se em dívidas, como em direitos. Em obrigações, como em pretensões. Em situações passivas nas ações, como em situações ativas. A sucessão, em princípio, é nos direitos e nas dívidas, ou no direito com os deveres e os ônus" (PONTES DE MIRANDA. Tratado de direito privado, Parte Especial, TOMO LV. Direito das sucessões: sucessão em geral. Sucessão legítima. 3. ed. § 5.614, capítulo 2. Rio de Janeiro: Borsoi, 1972, p. 179-180).

9 VENOSA, Sílvio de Salvo. Direito civil: direito das sucessões. 8. ed. São Paulo: Atlas, 2008, p. 1.

10 GONÇALVES, Carlos Roberto. Direito civil: direito das sucessões. 4. ed. v. 7. São Paulo: Saraiva, 2010, p. 19.

11 NERY JÚNIOR, Nelson. Código civil comentado. 8. ed. São Paulo: Revista dos Tribunais, 2011, p. 1.288.

12 "A transmissão dos direitos e obrigações do morto denomina-se sucessão; o conjunto formado pelo ativo e o passivo transmitidos denomina-se herança; a coisa certa deixada pelo morto a alguém determinado chama-se legado; quem deixa a herança ou o legado é o morto, ou autor da herança ou de cujus; quem recebe a herança é o herdeiro; o destinatário do legado é o legatário. A sucessão por morte pode dar-se a título singular (como, v.g., nos legados) - quando se transfere coisa certa destacada do patrimônio que pertenceu ao morto -, ou a título universal - quando se transfere a herança (universitas iuris)” (NERY JÚNIOR, Nelson. Código civil comentado. 8. ed. São Paulo: Revista dos Tribunais, 2011, p. 1.288). 
rer da manifestação de duas ou mais pessoas, se diz que a sucessão é inter vivos. Quanto aos direitos sucessórios, a transmissão só pode ocorrer em razão da morte, daí causa mortis". ${ }^{13}$

A sucessão causa mortis teve em época histórica remota "um sentido extrapatrimonial, importando para a família romana uma continuação da religião doméstica, em que o pater familias instituía na pessoa do herdeiro o novo titular da soberania familiar". Hodiernamente, a sucessão possui caráter predominantemente "econômico, caracterizando-se pela assunção dos direitos e deveres do de cujus pelos herdeiros e pelo recebimento dos legados pelos legatários”. ${ }^{14}$

Nesse sentindo, convém trazer a baila que o presente artigo limitar-se-á à sucessão causa mortis ou sucessão hereditária.
A sucessão causa mortis é aquela decorrente da morte de alguém que possui “decorrência lógica da propriedade, tal como caracterizada, dentre outros aspectos, pela perpetuidade e estabilidade da relação jurídica formada". ${ }^{15}$

A sucessão causa mortis origina-se com a morte real (decorrente da morte natural) ou presumida (decorrente da ausência da pessoa, ou seja, quando a mesma desaparece de seu domicílio sem deixar um procurador para administrar seus bens) da pessoa natural. ${ }^{16}$ Assim, uma vez aberta a sucessão, aplica-se o princípio da sai$\operatorname{sine}^{17}$, transmitindo-se a herança aos herdeiros legítimos e testamentários e, consequentemente, o domínio e a posse dos bens, direitos e obrigações do "de cujus". ${ }^{18}$ Podemos destacar que são pressupostos do direito suces-

13 DIAS, Maria Berenice. Manual das sucessões. São Paulo: Revista dos Tribunais, 2011, p. 99.

14 WALD, Arnold. Direito civil: direito das sucessões. v. 6. 15. ed. São Paulo: Saraiva, 2012, p. 20.

15 CAHALI, Francisco José; HIRONAKA, Giselda Maria Fernandes Novaes. Direito das sucessões. 4. ed. São Paulo: Revista dos Tribunais, 2012.

16 GONÇALVES, Carlos Roberto. Direito civil brasileiro: direito das sucessões. 4. ed. v. 7. São Paulo: Saraiva, 2010, p. 33-34.

17 Saisine: "palavra de origem francesa que significa agarrar, prender, apoderar-se" (DIAS, Maria Berenice. Manual das sucessões. São Paulo: Revista dos Tribunais, 2011, p. 107).

18 "A expressão latina de cujus é a abreviatura da frase de cujus sucessione (ou hereditatis) agitur, que significa 'aquele de cuja sucessão (ou herança) se trata"' (GONÇALVES, Carlos Roberto. Direito civil brasileiro: direito das sucessões. 4. ed. v. 7. São Paulo: Saraiva, 2010, p. 20.) 
sório causa mortis a morte de alguém, "titular de um patrimônio, e a sobrevida de outras pessoas, chamadas a recolher esse patrimônio, que recebe o nome de herança. ${ }^{19}$ Inexistindo patrimônio, não se pode falar em herança, e o fato morte não interessa ao direito sucessório". ${ }^{20}$ Nesse sentido, "a morte, a abertura da sucessão e a transmissão da herança aos herdeiros ocorrem num só momento"21.

Convém salientar os ensinamentos de Washington de Barros Monteiro:

A existência da pessoa natural termina com a morte (CC, art. 10). Verificado esse evento, abre-se-lhe a sucessão. Desde o óbito, sem solução de continuidade, opera-se a transmissão da herança, ainda que os herdeiros ignorem o fato do falecimento. Antes da morte, o titular da relação jurídica é o de cujus; depois dela passa a ser o herdeiro, legítimo ou testamentário. E é o próprio defunto que investe o sucessor no domínio e posse dos bens hereditários. Esse princípio vem expresso na regra tradicional do direito gaulês le mort saisit le vif. Quer dizer, instantaneamente, independente de qualquer formalidade, logo que se abre a sucessão investe-se o herdeiro no domínio e posse dos bens constantes do acervo hereditário.22

A sucessão causa mortis poderá ser classificada, no que tange aos seus efeitos como a título singular ("o testador deixa ao beneficiário um bem certo e determinado, denominado legado") ou a título universal ${ }^{23}$ ("quando o herdeiro é chamado a suceder na

19 "Herança é, na verdade, um somatório, em que se incluem os bens e as dívidas, os créditos e os débitos, os direitos e as obrigações, as pretensões e as ações de que era titular o falecido, e as que contra ele foram propostas, desde que transmissíveis” (GONÇALVES, Carlos Roberto. Direito civil brasileiro: direito das sucessões. 4. ed. v. 7. São Paulo: Saraiva, 2010, p. 20).

20 DIAS, Maria Berenice. Manual das Sucessões. São Paulo: Revista dos Tribunais, 2011, p. 31.

21 VELOSO, Zeno. Novo Código Civil comentado. Coordenação de Ricardo Fiuza. v. 6. São Paulo: Saraiva, 2002, p. 1.598.

22 MONTEIRO, Washington de Barros. Curso de direito civil. 30. ed. São Paulo: Saraiva, 1995, p. 15.

23 "Pode ocorrer tanto na sucessão legítima como na testamentária. [...] A sucessão legítima é sempre a título universal, porque transfere aos herdeiros a totalidade ou fração ideal do patrimônio do de cujus. A testamentária pode ser a título universal quando envolver coisa determinada e individualizada, conforme a vontade do testador" (GONÇALVES, Carlos Roberto. Direito civil brasileiro: direito das sucessões. 4. ed. v. 7. São Paulo: Saraiva, 2010, p. 44-45). 
totalidade da herança, fração ou parte alíquota dela”). ${ }^{24}$

O Direito das Sucessões possui grande importância no estudo do Direito, visto que a Carta Magna o erigiu ao status de direito fundamental, conforme preceitua o artigo $5^{\circ}$, inciso XXX, garantindo o direito à herança. ${ }^{25}$ Assim, após essa breve introdução a respeito do direito sucessório, passamos a estudar o direito hereditário do cônjuge.

\section{DIREITOS HEREDITÁRIOS DO CÔNJUGE}

O Código Civil de 2002 trouxe a baila inúmeras modificações, dentre elas, no ramo do direito sucessório, principalmente no que tange ao cônjuge supérstite. Podemos destacar o fato de o cônjuge ser considerado herdeiro necessário ${ }^{26}$, tendo direito à legítima. O cônjuge com a vigência do novo Código Civil passou a concorrer com descendentes e ascendentes e, também, passou a garantir o direito real de habitação. O atual Código Civil deu um grande passo no direito sucessório do cônjuge, dessa forma, passamos a analisar os principais pontos referentes à temática.

\section{A) Da legitimidade do cônjuge para suceder}

A legitimidade do cônjuge para suceder está condicionada ao preenchimento dos requisitos impostos pelo artigo $1.830^{27}$ do Código Civil de

24 GONÇALVES, Carlos Roberto. Direito civil brasileiro: direito das sucessões. 4. ed. v. 7. São Paulo: Saraiva, 2010, p. 44.

25 Art. 5, inciso XXX da Constituição Federal de 1988: "é garantido o direito de herança".

26 "[...] o cônjuge sobrevivente, no Código Civil de 1916 é herdeiro legítimo, mas facultativo, não necessário, ocupando o terceiro lugar na ordem de vocação hereditária” (VELOSO, Zeno. Direito hereditário do cônjuge e do companheiro. São Paulo: Saraiva, 2010, p. 20). Na vigência do Código Civil de 1916, o "cônjuge seria convocado na falta de sucessores na linha reta (ascendentes ou descendentes), privando os colaterais (CC/1916, art. 1.603). Por expressa previsão, não era considerado herdeiro necessário, mas sim facultativo, podendo ser privado da herança a critério do consorte, bastando, para tanto, que ele dispusesse, por testamento, da integralidade de seu patrimônio em favor de terceiros (CC/1916, art. 1.725) (CAHALI, Francisco José; HIRONAKA, Giselda Maria Fernandes Novaes. Direito das sucessões. São Paulo: Revista dos Tribunais, 2012, p. 187.)

27 Art. 1.830 do Código Civil de 2002: "Somente é reconhecido direito sucessório ao cônjuge sobrevivente se, ao tempo da morte do outro, não estavam separados judicial- 
2002. Assim, o cônjuge sobrevivente, a época da morte do outro não poderá estar separado judicial ou extrajudicialmente, divorciado ou separado de fato a mais de dois anos, salvo nos casos em que a convivência tornou impossível a manutenção do matrimônio, sem culpa do sobrevivente. Convém referir que a lei não faz referência ao separado extrajudicialmente, no entanto, os principais doutrinadores trazem essa possibilidade à tona, haja vista a disposição dessa modalidade de separação no artigo 1.124-A do Código de Processo Civil.

Nesse diapasão, convém referir que o cônjuge somente será herdeiro se:

a) não estiver separado judi-
cialmente, nem divorciado. A separação põe termo à sociedade conjugal, e o divórcio, ao vínculo. Em ambos os casos, o cônjuge não mais sucederá. Acertadamente, o diploma vigente afasta o antigo cônjuge da sucessão. Não seria lógico, já que os cônjuges não são parentes entre si, que rompida a sociedade ou o vínculo matrimonial existisse relação sucessória. Com o fim do casamento ou apenas da sociedade conjugal, não haveria nenhum motivo jurídico para chamar o antigo cônjuge à sucessão; b) não estiver separado de fato, há mais de dois anos. A separação de fato por mais de dois anos possibilita o divórcio e, então, como regra o cônjuge sobrevivente não será herdeiro. A lei prevê, entretanto, uma exceção. Se estiver separado de fato há mais de dois anos, poderá o cônjuge ser herdeiro, se provar que a convivência se tornou impossível sem sua culpa. Assim, mesmo separados de fato há mais de dois anos, o cônjuge sobrevivente poderá provar que a convivência com o de cujus se tornara impossível, sem sua culpa e, nesse caso, mesmo separado de fato, terá direito à sucessão. ${ }^{28}$

\section{B) Do cônjuge supérstite: herdeiro necessário e privilegiado}

Com o advento do Código Civil de $2002^{29}$, o cônjuge supérstite passou a ser considerado herdeiro necessário privilegiado assumindo uma destacada posição na ordem de vocação hereditária, ao contrário do que ocorria no Código Civil de 1916 em que o cônjuge podia ser excluído da sucessão pela via testamentária.

mente, sem separados de fato há mais de dois anos, salvo prova, neste caso, de que essa convivência se tornara impossível sem culpa do sobrevivente”.

28 LAGRASTA NETO, Caetano. Direito de família: novas tendências e julgamentos emblemáticos. São Paulo: Atlas, 2011, p. 120.

29 Art. 1.845 do Código Civil de 2002: “São herdeiros necessários os descendentes, os ascendentes e o cônjuge”. 
O Código Civil de 2002 refere que a sucessão legítima ocorrerá na seguinte ordem, conforme preceitua o artigo 1.829:

A sucessão legítima defere-se na ordem seguinte:

I-aos descendentes, em concorrência com o cônjuge sobrevivente, salvo se casado este com o falecido no regime da comunhão universal, ou no da separação obrigatória de bens (art. 1.640, parágrafo único); ou se, no regime da comunhão parcial, o autor da herança não houver deixado bens particulares;

II - aos ascendentes em concorrência com o cônjuge;

III - ao cônjuge sobrevivente;

IV - aos colaterais. (grifo nosso)

Assim, conforme o artigo 1.829, o cônjuge sobrevivente ocupa a terceira posição na ordem sucessória, concorrendo, caso existam, com os descen- dentes e ascendentes, e na inexistência destes, também herdará. ${ }^{30}$

Salienta-se, que no direito sucessório, o regime de bens adotado no casamento é irrelevante para o "chamamento do cônjuge como terceira classe", no entanto, na existência de descendentes, a concorrência sucessória observará o regime de bens; e na concorrência com os ascendentes, o regime de bens não interfere. ${ }^{31}$

\section{C) Do cônjuge supérstite: meeiro}

O cônjuge supérstite, além de herdeiro necessário é meeiro, tendo direito à meação caso seja casado em regime de comunhão universal de bens ${ }^{32}$, de comunhão parcial de bens ${ }^{33}$ ou de comunhão parcial dos aquestos. ${ }^{34}$ É importante referir que a meação não

30 DIAS. Maria Berenice. Manual das sucessões. São Paulo: Revista dos Tribunais, 2008, p. 170.

31 CATEB, Salomão de Araújo. Direito das sucessões. 4. ed. São Paulo: Atlas, 2007, p. 74.

32 Código Civil de 2002: Art. 1.667: “O regime de comunhão universal importa a comunicação de todos os bens presentes e futuros dos cônjuges e suas dívidas passivas, com as exceções do artigo seguinte".

33 Código Civil de 2002: Art. 1.658: "No regime de comunhão parcial, comunicam-se os bens que sobrevierem ao casal, na constância do casamento, com as exceções dos artigos seguintes”. Art. 1.660: "Entram na comunhão: I - os bens adquiridos na constância do casamento por título oneroso, ainda que só em nome de um dos cônjuges; II - os bens adquiridos por fato eventual, com ou sem o concurso de trabalho ou despesa anterior; III - os bens adquiridos por doação, herança ou legado, em favor de ambos os cônjuges; IV - as benfeitorias em bens particulares de cada cônjuge; V - os frutos dos bens 
se confunde com a herança, pois a meação decorre de direito emanado do casamento, ou seja, "pertence ao cônjuge por direito próprio, é efeito do regime de bens do casamento". ${ }^{35}$

Assim, destaca-se que com a morte, dependendo do regime de bens ${ }^{36}$ adotado no casamento, é possível verificar se existem ou não "bens em estado de mancomunhão" ${ }^{37}$, pois, "somente nos regimes em que há comunhão de patrimônios cabe falar em meação. O direito à meação não é renunciável, cessível ou penhorável na vigência

comuns, ou dos particulares de cada cônjuge, percebidos na constância do casamento, ou pendentes ao tempo de cessar a comunhão". Art. 1.662: "No regime da comunhão parcial, presumem-se adquiridos na constância do casamento os bens móveis, quando não se provar que o foram em data anterior."

34 Código Civil de 2002: Art. 1.672. "No regime de participação final nos aquestos, cada cônjuge possui patrimônio próprio, consoante disposto no artigo seguinte, e lhe cabe, à época da dissolução da sociedade conjugal, direito à metade dos bens adquiridos pelo casal, a título oneroso, na constância do casamento".

35 “O cônjuge meeiro já é titular da metade ideal dos bens, já é meeiro e não se torna meeiro porque o outro morreu; a viúva (ou o viúvo) pode ser meeira e não ser herdeira - ser herdeira sem ser meeira, e pode ser meeira e herdeira, vai depender do caso. Se, por exemplo, a pessoa casada sob o regime de comunhão universal falece, sua herança vai para os sucessores (herdeiros e legatários), abatida a meação ou ressalvada a meação, que não integra a herança, e pertence ao cônjuge sobrevivente. Se concorrer com ascendentes (CC, arts. 1.829, II, e 1.837), além de meeiro, o cônjuge é herdeiro" (VELOSO, Zeno. Direito hereditário do cônjuge e do companheiro. São Paulo: Saraiva, 2010, p. 43).

36 "No regime da comunhão universal, integra a meação todo o acervo: os bens particulares de ambos os cônjuges e os adquiridos, a qualquer título, depois do casamento. Na comunhão parcial, a meação é somente sobre os aquestos, ou seja, o patrimônio adquirido na constância do matrimônio. Mesmo na separação obrigatória (obrigatória porque é imposta por lei), existe direito à meação dos bens adquiridos durante a constância do enlace matrimonial, por força da Súmula 377 do STF. No regime da participação final dos aquestos, só cabe falar em meação quanto aos bens amealhados em comum durante o casamento. Os adquiridos em nome próprio, na vigência da sociedade conjugal, sujeitam-se à compensação, e não à divisão. Por fim, no regime da separação convencional, inexiste comunicação de patrimônios. Esta é a única hipótese em que, a princípio, não há direito à meação, ainda que a jurisprudência venha admitindo o direito à partilha mediante prova da contribuição na formação do acervo" (DIAS, Maria Berenice. Manual de Direito das Famílias. São Paulo: Revista dos Tribunais, 2012, p. 220).

37 Mancomunhão: "patrimônio comum pertencente a ambos em partes iguais" (DIAS, Maria Berenice. Manual de direito das famílias. São Paulo: Revista dos Tribunais, 2012, p. 230). 
do regime matrimonial, sendo nula a cláusula em pacto antenupcial que dispuser de forma contrária” ${ }^{38}$

\section{D) Do regime matrimonial de bens}

Convém destacar que, para o entendimento pormenorizado do direito sucessório brasileiro é necessário o estudo do regime matrimonial de bens, uma vez que esse é fator determinante na concorrência do cônjuge com os descendentes. Dessa forma, convém tecer breves comentários a respeito da temática dos regimes matrimoniais de bens, previsto nos arti- gos 1.639 e seguintes do Código Civil Brasileiro.

O regime de bens ${ }^{39}$ é um conjunto de regras/normas que regulam o patrimônio dos cônjuges - bens adquiridos na constância do casamento ou anteriormente -, sendo uma das "consequências jurídicas do casamento". ${ }^{40}$

O Código Civil de 2002, ao contrário do instituído no Código de $1916^{41}$, adotou como regime legal de bens a comunhão parcial de bens, conforme preceituam os artigos 1.658 a 1.666 do Código Civil. Assim, prevê a lei que na comunhão parcial de bens comunicam-se todos os bens amealhados durante o enlace matrimonial, "presumindo a lei ter sido adquirido

38 DIAS, Maria Berenice. Manual de direito das famílias. São Paulo: Revista dos Tribunais, 2012. p, 220 e 230.

39 "Regime de bens é o complexo de normas que disciplinam as relações econômicas entre marido e mulher, durante o casamento" (MONTEIRO, Washington de Barros. Curso de direito civil: direito das sucessões. 35. ed. v. 6. São Paulo: Saraiva, 2003, p. 183). "Os regimes de bens constituem, pois, os princípios jurídicos que disciplinam as relações econômicas entre os cônjuges, na constância do matrimônio" (PEREIRA, Caio Mário da Silva. Instituições de direito civil. 12. ed. v. 6. Rio de Janeiro: Forense, 2000, p. 187-188). "Regras e princípios administram o trânsito patrimonial dos bens no casamento. É mais que o complexo de normas sobre relações econômicas. O direito regula os efeitos que das relações decorrem sob a nomenclatura dos regimes matrimoniais de bens. O governo dos bens pretéritos, dos presentes e dos futuros, o objeto material do casamento e sua dinâmica" (FACHIN, Luiz Edson. Direito de família: elementos críticos à luz do novo Código Civil brasileiro. 2. ed. Rio de Janeiro: Renovar, 2003, p. 181). 40 DIAS, Maria Berenice. Manual das sucessões. São Paulo: Revista dos Tribunais, 2011, p. 99.

41 O regime de bens adotado na vigência do Código Civil de 1916 era a comunhão universal de bens, ou seja, a fusão dos bens do casal, comunicando-se os bens presentes e futuros. 
pelo esforço comum do par". ${ }^{42}$ No entanto, não podemos nos furtar de referir os demais regimes presentes no Código Civil atual, quais sejam o regime da comunhão universal de bens - artigos 1.667 a 1.671 do Código Civil, o regime de separação de bens - convencional elencado nos artigos 1.687 e 1.688 do Código Civil ou obrigatório referido no artigo 1.641 do Código Civil; e o regime da participação final nos aquestos - artigos 1.672 a 1.686 do Código Civil.

No direito das sucessões, o cônjuge sobrevivente, independente do regime adotado no casamento, "é chamado a recolher a herança” quando não há descendentes ou ascendentes e se, "ao tempo da morte do outro, não estavam separados judicialmente, nem separados de fato há mais de 2 (dois) anos, salvo prova, nesse caso, de que o rompimento não se deu por culpa do sobrevivente (arts. 1.838 e 1.830)" ${ }^{43}$ Nesse caso, o cônjuge sobrevivente torna-se "herdeiro necessário, único e universal, desde que preenchidos os requisitos legais gerais do art. 1.830". ${ }^{44}$

\section{E) Da concorrência sucessória do cônjuge com os descendentes do autor da herança}

A ordem de vocação hereditária ocorrerá por classes (descendentes, ascendentes, cônjuge e colaterais), assim, a ordem mais perto exclui a mais distante. ${ }^{45}$ Dessa forma, aberta a sucessão, sucedem primeiramente, os descendentes ${ }^{46}$, uma vez que esses são considerados "herdeiros por excelência”, "adquirindo os bens por direito próprio" ${ }^{47} \mathrm{Na}$ presença de

42 DIAS, Maria Berenice. Manual de direito das famílias. São Paulo: Revista dos Tribunais, 2012, p. 236.

43 CATEB, Salomão de Araújo. Direito das sucessões. 4. ed. São Paulo: Atlas, 2007, p. 73.

44 DINIZ, Maria Helena. Curso de direito civil brasileiro. 22. ed. v. 6. São Paulo: Saraiva, 2008, p. 117.

45 GONÇALVES, Carlos Roberto. Direito civil brasileiro: direito das sucessões. 4. ed. v. 7. São Paulo: Saraiva, 2010, p. 161.

46 Descendentes são os filhos, netos, bisnetos, trinetos, tetranetos, ou seja ad infinitum. 47 DINIZ, Maria Helena. Curso de direito civil brasileiro. 22. ed. v. 6. São Paulo: Saraiva, 2008, p. 107. 
descendentes ${ }^{48}$, serão afastados todos os demais herdeiros das classes subsequentes, salvo a "hipótese de concorrência com cônjuge sobrevivente ou companheiro". ${ }^{49}$

Assim, podemos destacar que:

A lei, ao colocar os descendentes em primeiro lugar na sucessão, segue uma ordem natural e afetiva. Normalmente, os vínculos afetivos com os descendentes são maiores, sendo eles a geração mais jovem à época da morte. Na classe dos descendentes, há o direito de representação, que funciona como uma forma de igualar a atribuição da herança as estirpes existentes (descendentes de cada filho do morto)..$^{50}$

É importante frisar que somente poderão suceder os filhos havidos (concebidos) até a data do falecimento do de cujus, salvo se houver dispo- sição de última vontade e, desde que vivos na abertura da sucessão, conforme preceitua o artigo 1.799, inciso I do Código Civil de 2002. Também poderá ocorrer a sucessão nos casos de inseminação artificial homóloga post mortem, no caso de embriões crioconservados - quando houver nascimento com vida, o nascituro terá seus direitos sucessórios assegurados.

Destaca-se, conforme referido anteriormente, que o cônjuge, nos casos determinados por lei, poderá concorrer com os descendentes na sucessão. Nesse sentido, o cônjuge sobrevivente, estando casado com o de cujus no regime de comunhão parcial de bens, e tendo o cônjuge falecido bens particulares, a concorrência ocorrerá em tais bens, "devendo os bens comuns (meação) serem partilhados exclusivamente entre os descendentes". ${ }^{51}$ As-

48 “"...] na linha descendente, os filhos sucedem por cabeça, e os outros descendentes, por cabeça ou por estirpe, conforme se achem ou não no mesmo grau (art. 1.835). O que a lei estipula é que, havendo desigualdade de graus de parentesco na linha descendente, a herança pode ser atribuída a herdeiros de dois graus diversos” (VENOSA, Sílvio de Salso. Direito civil brasileiro: direito das sucessões. 8. ed. v. 7. São Paulo: Atlas, 2008. p. 113-119).

49 GONÇALVES, Carlos Roberto. Direito civil brasileiro: direito das sucessões. 4. ed. v. 7. São Paulo: Saraiva, 2010, p. 161.

50 VENOSA, Sílvio de Salso. Direito civil brasileiro: direito das sucessões. 8. ed. v. 7. São Paulo: Atlas, 2008, p. 113-114.

51 Enunciado 270 aprovado em dezembro de 2004, após a conclusão da III Jornada de Direito Civil, promovida pelo Conselho da Justiça Federal/Centro de Estudos Judiciários em Brasília/DF: “O art. 1.829, inc. I, só assegura ao cônjuge sobrevivente o direito de concorrência com os descendentes do autor da herança quando casados no regime da separação convencional de bens ou, se casados nos regimes da comunhão parcial ou 
sim, se os cônjuges forem casados nos regimes de separação convencional de bens, comunhão universal de bens ou comunhão parcial de bens quando o autor da herança não deixou bens particulares, não concorrerá com os descendentes.

É importante referir que as posições doutrinárias em relação à concorrência do cônjuge com os descendentes são diversas, não havendo unanimidade, assim, convém trazer à baila alguns posicionamentos. Segundo Salomão de Araújo Cateb, para que o cônjuge concorra com os descendentes, o regime de bens adotado no casamento não poderá ser de comunhão universal de bens ou de separação convencional de bens. Sendo, de comunhão parcial, o de cujus não poderá deixar bens particulares. "Essa nova posição reflete uma tendência do mundo ocidental, beneficiando o cônjuge que ajudou na construção da família, do patrimônio, na criação dos filhos e no sucesso do lar em sua totalidade". ${ }^{52}$ Para Maria Helena Diniz, o cônjuge sobrevivente concorrerá com os descendentes, quando casado no regime de comunhão parcial de bens, na totalidade da herança, ou seja, sobre todo o acervo hereditário, "porque a lei não diz que a herança do cônjuge só recai sobre os bens particulares do de cujus e para atender ao princípio da operabilidade, tornando mais fácil o cálculo para a partilha da parte cabível a cada herdeiro". Segundo a autora, a "herança é indivisível, deferindo-se como um todo unitário, ainda que vários sejam os herdeiros". ${ }^{53}$ Seguem o entendimento de que o cônjuge sobrevivente, casado no regime de comunhão parcial de bens, concorrerá com os descendentes sobre todo o acervo hereditário os seguintes doutrinadores: Guilherme Calmon Nogueira da Gama, Inácio de Carvalho Neto, Luiz Paulo Vieira de Carvalho e Mário Roberto Carvalho de Faria. ${ }^{54}$

$\mathrm{O}$ entendimento majoritário refere que o cônjuge sobrevivente, no regime de comunhão parcial de bens, somente concorrerá sobre os bens

participação final nos aquestos, o falecido possuísse bens particulares, hipóteses em que a concorrência se restringe a tais bens, devendo os bens comuns (meação) ser partilhados exclusivamente entre os descendentes”.

52 CATEB, Salomão de Araújo. Direito das sucessões. 4. ed. São Paulo: Atlas, 2007, p. 76.

53 DINIZ, Maria Helena. Curso de direito civil brasileiro. 22. ed. v. 6. São Paulo: Saraiva, 2008, p. 107.

54 CAHALI, Francisco José; HIRONAKA, Giselda Maria Fernandes Novaes. Direito das sucessões. São Paulo: Revista dos Tribunais, 2012, p. 225-226. 
particulares deixados pelo de cujus, uma vez que, quanto aos bens comuns já é meeiro e "não seria justo que ainda viesse a ser herdeiro, concorrendo com os descendentes do de cujus, sobre esses bens comuns, além dos particulares, mormente se não houver filhos comuns, mas filhos só do falecido". ${ }^{5}$ Seguem esse entendimento, também, Eduardo de Oliveira Leite, Gisela Maria Fernandes Hironaka, José Fernando Simão, Maria Berenice Dias, Maria Helena Daneluzzi, Rolf Madaleno, dentre outros. Também, segue esse entendimento a $7^{\text {a56 }}$ e a $8^{\mathrm{a} 57}$ Câmara Cível do Tribunal de Justiça do Rio Grande do Sul e o Superior Tribunal de Justiça. ${ }^{58}$

55 VELOSO, Zeno. Direito hereditário do cônjuge e do companheiro. Coordenação de Ricardo Fiuza. São Paulo: Saraiva, 2002, p. 46.

56 AGRAVO DE INSTRUMENTO. SUCESSÃO DO CÔNJUGE. ART. 1829, I DO CÓDIGO CIVIL. CASAMENTO SOB O REGIME DA COMUNHÃO PARCIAL DE BENS. MEAÇÃO SOBRE OS AQUESTOS E DIREITOS HEREDITÁRIOS APENAS SOBRE OS BENS PARTICULARES. Quando casados sob o regime da comunhão parcial de bens, a sucessão do cônjuge defere-se ao sobrevivente em concorrência com os descendentes apenas em relação aos bens particulares, uma vez que sobre os bens comuns, já lhe tocará a meação. Negaram provimento. Unânime. (Agravo de Instrumento $\mathrm{n}^{\circ}$ 70045853652, Sétima Câmara Cível, Tribunal de Justiça do RS. Relator: Liselena Schifino Robles Ribeiro. Julgado em 28/03/2012).

57 Agravo de instrumento. Sucessão do cônjuge. art. 1829, I do Código Civil. Casamento sob o regime da comunhão parcial de bens. Meação Sobre os aquestos e direitos hereditários apenas sobre os bens particulares. Quando casados sob o regime da comunhão parcial de bens, a sucessão do cônjuge defere-se ao sobrevivente em concorrência com os descendentes apenas em relação ao bens particulares, uma vez que sobre os bens comuns, já lhe tocará a meação. Negaram provimento. Unânime. (Agravo de instrumento $n^{\circ}$ 70046234498, Oitava Câmara Cível, Tribunal de Justiça do RS. Relator: Luiz Felipe Brasil Santos. Julgado em 26/01/2012).

58 CIVIL. SUCESSÃO. CÔNJUGE SOBREVIVENTE E FILHA DO FALECIDO. CONCORRÊNCIA. CASAMENTO. COMUNHÃO PARCIAL DE BENS. BENS PARTICULARES. CÓDIGO CIVIL, ART. 1829, INC. I. DISSÍDIO NÃO CONFIGURADO. 1. No regime da comunhão parcial de bens, o cônjuge sobrevivente não concorre com os descendentes em relação aos bens integrantes da meação do falecido. Interpretação do art. 1829, inc. I, do Código Civil. 2. Tendo em vista as circunstâncias da causa, restaura-se a decisão que determinou a partilha, entre o cônjuge sobrevivente e a descendente, apenas dos bens particulares do falecido. 3. Recurso especial conhecido em parte e, nesta parte, provido. [...] I - Em razão da incongruência da redação do art. 1.829, inciso I, do CC/02, a doutrina brasileira possui relevantes vozes defendendo correntes distintas acerca da interpretação da sucessão do cônjuge quando casado sob o regime comunhão parcial de bens. II - Ao enfrentar o presente tema, este Colendo Supe- 
Nesse sentido, trazemos à baila 0 exemplo dado pelo Desembargador Luis Felipe Brasil Santos:
Um singelo exemplo ajudará a compreender as dificuldades possíveis. Imagine-se, primeiramente, a situa-

rior Tribunal de Justiça, diante de seu papel de unificador do direito federal, deve manter a integridade do sistema normativo de modo a prevalecer o seu entendimento por ser o intérprete oficial dos enunciados normativos. A Corte Especial deste STJ decidiu que “[...] o conteúdo da norma não é, necessariamente, aquele sugerido pela doutrina, ou pelos juristas ou advogados, e nem mesmo o que foi imaginado ou querido em seu processo de formação pelo legislador; o conteúdo da norma é aquele, e tão somente aquele, que o Poder Judiciário diz que é”. (Corte Especial, AI nos ERESP 644.736/PE, MIN. TEORI ALBINO ZAVASCKI, julgado em 06.06.2007). III - A jurisprudência desta Eg. Corte de Justiça cada vez mais se firma no sentido de que não há como dissociar o direito sucessório dos regimes de bens do casamento, de modo que se tenha após a morte, o que, em vida, não se pretendeu. IV - Malfere legislação federal, portanto, a decisão que confere ao cônjuge supérstite, além de sua meação, direitos sobre todo o acervo da herança do de cujus, desrespeitando a autonomia de vontade do casal quando da escolha do regime de comunhão parcial de bens. V - Na nova ordem de vocação hereditária do Código Civil de 2002, o caráter protecionista da lei ao cônjuge sobrevivente não deve ser confundida como um privilégio de modo a prejudicar os demais herdeiros necessários na ordem de sucessão. VI - Na sucessão legítima sob o regime de comunhão parcial de bens, a regra é: ocorrendo o evento morte de um dos cônjuges, ao sobrevivente é garantida a meação dos bens comuns (havidos na constância do casamento). Não concorre ele com os descendentes em relação à herança (bens comuns do falecido), tampouco em relação aos bens particulares, pois o sobrevivo, por força do regime de casamento (comunhão parcial), já encontra-se amparado pela meação. Os bens particulares dos cônjuges são, em regra, incomunicáveis em razão do regime convencionado em vida pelo casal. VII - A máxima que prevalece no direito sucessório é no sentido de "quem é meeiro não deve ser herdeiro", conforme ensinamentos do Professor MIGUEL REALE (Citado por EDUARDO DE OLIVEIRA LEITE, in A Nova Ordem de Vocação Hereditária e a Sucessão dos Cônjuges, RT, 815, São Paulo, Set. 2003. pg. 33). VIII - É excepcional a concorrência entre os descendentes e o cônjuge sobrevivente casado sob o regime de comunhão parcial de bens com o de cujus, prevista na parte final do art. 1.829, inciso I, do CC/02. Subsiste a concorrência, e tão somente nessas hipóteses, se inexistentes bens comuns ou herança a partilhar, e o falecido deixar apenas bens particulares, tendo em vista o caráter protecionista da norma que visa não desamparar o sobrevivente nessas situações excepcionais. IX - Todavia, na hipótese sub examine, nos estreitos limites estabelecidos pelo pedido em sede de recurso especial, embora entenda como não devidos, a única filha do de cujus, ora recorrente, expressamente pugna para que os bens anteriores do falecido (particulares) sejam divididos entre ela própria e o cônjuge sobrevivente, não se tem como obstaculizar essa pretensão em sede recursal, pois o direito lhe é concedido por livre vontade e de natureza renunciável. X - Rec. Especial conhecido em parte e, nessa extensão, provido. (STJ, Resp 974.241/DF, Rel. Min. Honildo A. de Mello Castro. Julg. 07/10/11). 
ção de um casal, com um filho, cujo único patrimônio seja constituído pelo apartamento onde reside (no valor de $\mathrm{R} \$ 99.000,00)$ adquirido na constância do casamento. Nesse caso, falecendo o varão, e não havendo bens particulares, a mulher não concorrerá com o filho, recebendo apenas sua meação (correspondente, no caso, a R\$ 49.500,00). Admitamos, agora, que, além desse apartamento, o autor da herança fosse proprietário de uma bicicleta (no valor de $\mathrm{R} \$$ $1.000,00)$, que, por ter sido adquirida em sub-rogação de um bem preexistente ao casamento, constitui bem particular (art. 1.659, II). Nessa hipótese, existindo bem particular, o cônjuge concorrerá com o descendente, em igualdade de condições, recebendo, portanto, - além de sua meação sobre o apartamento (R\$ 49.500,00) - a título de herança, a metade de todos os bens deixados pelo "de $\mathrm{Cu}$ jus”, ou seja, mais R\$25.500,00. O total dos bens que caberão ao cônjuge sobrevivente (meação + quinhão hereditário) corresponderá, neste segundo caso, a R\$ 75.000,00, ficando o filho com R\$25.000,00. Como se vê desse exemplo, a simples existência de uma bicicleta (na condição de bem particular, no valor de $1 \%$ do total dos bens) faz com que surja o direito do cônjuge de concorrer com o descendente, aumentando desproporcionalmente o valor que lhe caberá, que passa de $\mathrm{R} \$$ 49.500,00 (na primeira situação, em que recebe apenas a meação) para R \$ 75.000,00 (na segunda situação, onde, por existir bem particular, concorre com o descendente)! Assim, percebe-se que a existência de uma simples bicicleta, trazida pelo autor da herança, definirá a condição de herdeiro concorrente do cônjuge sobre o total da herança deixada pelo de cujus, ou seja, a distribuição dos percentuais ficará desproporcional, em virtude de um objeto de tão irrisório valor. ${ }^{59}$

Convém referir que quando o cônjuge sobrevivente concorrer com os descendentes do de cujus, deverá ser destinado um "quinhão igual ao dos que sucederam por cabeça, não podendo a sua quota ser inferior à quarta parte da herança, se for

59 SANTOS. Luiz Felipe Brasil. A sucessão dos cônjuges no novo Código Civil. IBDFAM. Publicado em: 31/03/2003. Disponível em: http://www.ibdfam.org.br/?artigos\&artigo=85. Acessado em: 27 maio 2012. 
ascendente dos herdeiros com que concorrer" ${ }^{\prime 60,61}$, conforme preceitua o artigo 1.832 do Código Civil de 2002. Assim, verificam-se duas hipóteses no que tange aos herdeiros necessários, ou seja, quando há filhos comuns ou filhos exclusivos do de cujus:

a) a primeira, de os descendentes do morto não serem descendentes do cônjuge sobrevivente. Nesse caso, tantos quantos sejam os herdeiros do mesmo grau descendente receberão com o cônjuge sobrevivente quotas iguais da herança. Se um dos herdeiros for falecido [...] os descendentes deste (netos do avô de cuja herança se trata) o sucederão, por representação (CC 1851 c/c 1854), mas isso não interfere na quota-parte do cônjuge supérstite; b) a segunda hipótese versa sobre concorrerem à herança o cônjuge sobrevivente com descendentes do morto, que também são os seus. Nesse caso, o cônjuge terá direito igual à mesma parte devida aos herdeiros descendentes, desde que sua quota não venha a ser inferior à quarta parte da herança partilhada. ${ }^{62}$

Também, é importante referir à hipótese do de cujus ter deixado filhos exclusivos e filhos comuns. Nesse caso, como não há referência na lei a respeito da filiação híbrida, coube à doutrina e à jurisprudência esclarecer. Dessa forma, quando o cônjuge sobrevivente não é ascendente de todos os filhos deixados pelo de cujus, estamos diante de um caso de filiação híbrida, assim, “a quota hereditária mínima (1/4) não é cabível, fazendo-se a partilha por cabeça entre a viúva ou o viúvo e os descendentes do de cujus". ${ }^{63}$ No entanto, existem outras posições doutrinárias contrárias ao aventado anteriormente, que referem

60 "[...] se o falecido deixou até três filhos, a partilha se faz por cabeça, dividindo-se a herança, em partes iguais, entre os filhos e o cônjuge. No caso de o de cujus possuir quatro filhos ou mais, e tendo de ser reservada a quarta parte da herança à viúva ou ao viúvo, os filhos repartirão o restante. Por exemplo: o autor da herança tem quatro filhos. Nesse caso, o cônjuge sobrevivente fica com um quarto da herança, e os três quartos restantes são destinados aos quatro filhos; e não haverá igualdade de quinhões: a quota cônjuge é maior que a do descendente; a divisão já não é per capita - a partilha é irregular” (VELOSO, Zeno. Direito hereditário do cônjuge e do companheiro. Coordenação de Ricardo Fiuza. São Paulo: Saraiva, 2002, p. 51).

61 VELOSO, Zeno. Direito hereditário do cônjuge e do companheiro. Coordenação de Ricardo Fiuza. São Paulo: Saraiva, 2002, p. 46.

62 NERY JÚNIOR, Nelson; ANDRADE NERY, Rosa Maria. Código Civil comentado. 8. ed. São Paulo: Revista dos Tribunais, 2011, p. 1.325.

63 VELOSO, Zeno. Direito hereditário do cônjuge e do companheiro. Coordenação de Ricardo Fiuza. São Paulo: Saraiva, 2002, p. 69. 
que nos casos de filiação híbrida se "aplica a garantia mínima da quarta parte em favor do cônjuge”, ${ }^{64}$

Em novembro de 2011, foi aprovado o Enunciado 526, após a conclusão da V Jornada de Direito Civil, promovida pelo Conselho da Justiça Federal/Centro de Estudos Judiciários em Brasília/DF, referindo que "na concorrência entre o cônjuge e os herdeiros do de cujus, não será reservada a quarta parte da herança para o sobrevivente no caso de filiação híbrida".

Agora, passaremos a analisar de forma pormenorizada a concorrência do cônjuge sobrevivente com os descendentes, conforme regime de bens adotado no casamento.

\section{Comunhão universal de bens}

O regime de comunhão universal de bens na vigência do Código
Civil de 1916 era o regime legal de bens adotado. Atualmente, o regime de comunhão universal de bens disciplinado nos artigos 1.667 a 1.671 do Código Civil de 2002 somente poderá ser adotado mediante pacto antenupcial pelos nubentes. No regime de comunhão universal de bens ocorrerá uma fusão dos bens do casal, ou seja, todos os bens trazidos pelos nubentes se somarão aos bens adquiridos na constância do casamento - por doação, herança ou a título oneroso -, formando um único patrimônio. ${ }^{65}$

No regime de comunhão universal de bens ${ }^{66}$, o cônjuge sobrevivente não concorrerá com os descendentes, uma vez que este terá direito à meação. ${ }^{67}$ "Parte-se do princípio pelo qual em havendo meação, afastada estará a sucessão por concorrência com os descendentes" ${ }^{68}$ Assim, ao se garantir a meação ao cônjuge sobrevivente, este já recebeu a proteção necessária,

64 VENOSA, Sílvio de Salso. Direito civil: direito das sucessões. 8. ed. v. 7. São Paulo: Atlas, 2008, p. 113-119.

65 DIAS. Maria Berenice. Manual das sucessões. São Paulo: Revista dos Tribunais, 2011, p. 240.

66 “Exemplificativamente: em patrimônio correspondente a $\mathrm{R} \$ 100.000,00$, no regime de comunhão universal de bens, biparte-se o acervo em duas partes: R\$ 50.000,00 correspondente à meação e os outros R \$50.000,00 correspondentes à cota do de cujus” (LEITE, Eduardo de Oliveira. Direito civil aplicado: direito das sucessões. 2. ed. v. 6. São Paulo: Revista dos Tribunais, 2012, p. 112).

67 LAGRASTA NETO, Caetano. Direito de família: novas tendências e julgamentos emblemáticos. São Paulo: Atlas, 2011, p. 121.

68 LAGRASTA NETO, Caetano. Direito de família: novas tendências e julgamentos emblemáticos. São Paulo: Atlas, 2011, p. 120. 
assim, "não há razão para que seja ainda herdeiro, concorrendo com filhos do falecido". ${ }^{69}$

\section{Separação obrigatória de bens}

O regime de separação obrigatória de bens previsto no artigo 1.641 do Código Civil de 2002, como regra geral, somente poderá ser adotado por meio de pacto antenupcial. No entanto, na vigência do Código Civil de 1916, esse regime poderia ser adotado pelos nubentes. Como exceção, podemos destacar o previsto no artigo 1.641 do Código Civil de 2002 em que a lei impõe o regime para determinados casos:

Art. 1.641. É obrigatório o regime da separação de bens no casamento:

I - das pessoas que o contraírem com inobservância das causas suspensivas da celebração do casamento;

II - da pessoa maior de 70 (setenta) anos;

III - de todos os que dependerem, para casar, de suprimento judicial.
No regime de separação total de bens o acervo patrimonial é dividido pelos bens da esposa e pelos bens do marido, assim, "cada um é titular de seu próprio patrimônio, quer tenha sido adquirido antes ou na constância do casamento. Quando da separação, nada há a dividir, e cada um ficará com os bens que lhe são próprios". ${ }^{70}$

Convém destacar que na separação obrigatória, o cônjuge sobrevivente não concorrerá com os descendentes, assim, podemos referir que, "se a lei impediu a meação em vida, não admitiria a meação entre descendentes e cônjuge mortis causa". ${ }^{71}$ Segundo o artigo 1.929, inciso I, do Código Civil, a totalidade do espólio caberá aos descendentes do de cujus, uma vez que não há meação. Podemos referir que "os bens são incomunicáveis, os patrimônios ficam separados, cada cônjuge é dono, possuidor e administrador exclusivo dos respectivos bens, e, igualmente, não é herdeiro", ${ }^{72}$ Ainda, durante a vigência do Código Civil de 1916, foi editada a Súmula 377 pelo Supremo Tribunal

69 GONÇALVES, Carlos Roberto. Direito civil brasileiro: direito das Sucessões. 4. ed. v. 7. São Paulo: Saraiva, 2010, p. 151.

70 DIAS. Maria Berenice. Manual das sucessões. São Paulo: Revista dos Tribunais, 2011, p. 223.

71 LAGRASTA NETO, Caetano. Direito de família: novas tendências e julgamentos emblemáticos. São Paulo: Atlas, 2011, p. 121.

72 VELOSO, Zeno. Direito hereditário do cônjuge e do companheiro. São Paulo: Saraiva, 2010, p. 17. 
Federal referindo que "no regime da separação legal de bens, comunicam-se os adquiridos na constância do casamento". Com a edição do Código Civil de 2002, passou-se a discutir a validade dessa Súmula, no entanto, conforme prevê Zeno Veloso, “embora o cônjuge sobrevivente não concorra com os descendentes se o regime é o da separação obrigatória (CC, 1.829, I), pode pleitear a meação dos bens adquiridos com o esforço comum após o casamento". ${ }^{73}$ No entanto, há doutrinadores que entendem que "não faria sentido, com efeito, permitir ao cônjuge eventualmente receber, a título de herança, os mesmos bens que não podiam comunicar-se no momento da constituição do vínculo matrimonial”. ${ }^{74}$

\section{Comunhão parcial de bens}

O regime de comunhão parcial de bens, previsto nos artigos 1.658 a 1.666 do Código Civil de 2002 é o regime legal de bens adotado atualmente, quando os nubentes não optarem por meio de pacto antenupcial por outro regime para regular seu enlace matrimonial.

O regime de comunhão parcial de bens trata-se de um regime de "separação quanto ao passado e de comunhão quanto ao futuro". ${ }^{75}$ Convém salientar, também que:

No regime da comunhão parcial, são três blocos: os particulares de cada um, ou seja, (1) os bens do marido e (2) os da mulher, adquiridos por cada um antes do casamento; e (3) os aquestos - bens comuns adquiridos após o enlace matrimonial, por ambos ou qualquer dos cônjuges. Solvido o casamento, cada um ficará com seus bens particulares e mais a metade do patrimônio comum. ${ }^{76}$

Na comunhão parcial de bens, quando o de cujus não deixou bens particulares, o cônjuge sobrevivente não concorrerá com os descendentes, haja vista que os bens comuns deixados compõem a meação do sobrevivente. “Assim, comunhão parcial sem bens particulares se aproxima da comunhão universal. Em havendo mea-

73 VELOSO, Zeno. Direito hereditário do cônjuge e do companheiro. São Paulo: Saraiva, 2010, p. 17.

74 GONÇALVES, Carlos Roberto. Direito civil brasileiro: direito das sucessões. 4. ed. v. 7. São Paulo: Saraiva, 2010, p. 152.

75 DIAS. Maria Berenice. Manual das sucessões. São Paulo: Revista dos Tribunais, 2011, p. 235-236.

76 DIAS. Maria Berenice. Manual das sucessões. São Paulo: Revista dos Tribunais, 2011, p. 223. 
ção, não há que se falar em sucessão, pois o cônjuge sobrevivente não estará desamparado."77

$\mathrm{Na}$ comunhão parcial de bens, quando o de cujus deixou bens particulares, o cônjuge sobrevivente concorrerá com os descendentes, no que tange aos bens particulares, e não na totalidade dos bens deixados pelo de cujus. $^{78}$ Dessa forma, salienta-se que o “quinhão hereditário correspondente à meação do falecido nos bens comuns será, assim, repartido exclusivamente entre os descendentes, sendo que o cônjuge somente será sucessor nos bens particulares". ${ }^{79}$

Assim, conclui-se que a concorrência hereditária do cônjuge com os descendentes ocorrerá apenas se:

no casamento sob o regime da comunhão parcial, houver bens particulares, porque sobre estes, então sim, é que incidirá o direito sucessório concorrente, da mesma forma como se dá no regime da separação convencional de bens. [...] Não teria sentido atribuir ao cônjuge aquinhoado com a meação participação na herança sobre todos os bens, pois então receberia mais do que se tivesse sido casado no regime da comunhão universal. Por isso o entendimento que, predominante na doutrina, beneficia o cônjuge tão somente sobre os bens particulares, exatamente como seria se casado fosse no regime de separação convencional de bens, já que, sobre esses mesmos bens, não lhe assiste o direito de meação. ${ }^{80}$

\section{Participação final dos aquestos}

O regime de participação final nos aquestos, previsto nos artigos 1.672 a 1.686 do Código Civil de 2002, "trata-se de regime misto, híbrido, que reclama pacto antenupcial”, em que cada cônjuge possui seu patrimônio próprio e os bens comuns adquiridos por ambos, a título oneroso, na constância do casamento. ${ }^{81}$ É importante destacar que:

77 LAGRASTA NETO, Caetano. Direito de família: novas tendências e julgamentos emblemáticos. São Paulo: Atlas, 2011, p. 122.

78 LAGRASTA NETO, Caetano. Direito de família: novas tendências e julgamentos emblemáticos. São Paulo: Atlas, 2011, p. 122.

79 GONÇALVES, Carlos Roberto. Direito civil brasileiro: direito das sucessões. 4. ed. v. 7. São Paulo: Saraiva, 2010, p. 243.

80 OLIVEIRA, Euclides Benedito de. Direito de herança: a nova ordem da sucessão. São Paulo: Saraiva, 2005, p. 108.

81 DIAS. Maria Berenice. Manual das sucessões. São Paulo: Revista dos Tribunais, 2011, p. 223. 
No regime da participação final dos aquestos, existem cinco universalidades de bens: os particulares que cada um possuía antes de casar, ou seja, (1) os bens do homem e (2) os da mulher. Depois do casamento, surgem mais três conjuntos: (3) o patrimônio próprio do marido; (4) o adquirido pela mulher em seu nome; e (5) os bens comuns adquiridos pelo casal durante o casamento. No caso de dissolução do vínculo, cada cônjuge ficará com seus bens particulares e com a metade dos comuns. Com relação aos bens próprios de cada um, adquiridos durante o casamento, serão compensados os respectivos valores. No caso de desequilíbrio, fica um com crédito junto ao outro. ${ }^{82}$

Nelson Nery Junior fala das características do regime em comento:

Pelo regime de participação final dos aquestos, os cônjuges vivem sob verdadeira separação de bens, vale dizer, cada cônjuge tem a livre administração de seus próprios bens, enquanto durar a sociedade conjugal. A eficácia desse regime de bens quanto à efetiva participação final dos aquestos só surge com o fato jurídico da dissolução da sociedade conjugal. Antes disso o casal vive sob o regime da separação de bens. Na constância da sociedade conjugal, tudo que os cônjuges adquirem integrará, respectivamente, a massa do patrimônio de cada um. No momento da dissolução da sociedade conjugal serão apurados os bens adquiridos na constância da sociedade conjugal, a título oneroso, e divididos pela metade para cada um dos cônjuges. ${ }^{83}$

Na participação final nos aquestos, o cônjuge sobrevivente concorrerá com os descendentes, no que tange aos bens particulares, ou seja, aos bens adquiridos antes do casamento e aqueles adquiridos durante o matrimônio, sem a participação financeira do outro cônjuge.

\section{Separação convencional de bens}

A separação convencional de bens trata-se de regime adotado pelos nubentes por meio de pacto antenupcial em que haverá a "divisão dos bens de cada cônjuge”. Nesse regime, não se comunicam os bens adquiridos antes ou depois do casamento pelos cônjuges. ${ }^{84}$

82 DIAS. Maria Berenice. Manual das sucessões. São Paulo: Revista dos Tribunais, 2011, p. 223.

83 NERY JÚNIOR, Nelson; ANDRADE NERY, Rosa Maria. Código Civil comentado. 8. ed. São Paulo: Revista dos Tribunais, 2011, p. 1.221.

84 GAGLIANO, Pablo Stolze; PAMPLONA FILHO, Rodolfo. Novo curso de direito civil. 2. ed. v. 6. São Paulo: Revista dos Tribunais, 2012, p. 371. 
$\mathrm{Na}$ separação convencional de bens, não haverá meação e, nesse caso, o cônjuge sobrevivente concorrerá com os descendentes do de cujus. ${ }^{85}$

\section{F) Da sucessão do cônjuge em concorrência com os ascendentes}

Destaca-se que na ausência de descendentes a sucessão será realizada pelos ascendentes ad infinitum do de cujus, ou seja, a segunda classe de sucessíveis, seus pais, avós, bisavós, tataravós etc. Também, nesse caso, o "princípio da proximidade é a regra: o parente de grau mais próximo exclui o de grau mais remoto (art. 1.836, §1. ${ }^{\circ}$ ), mas não se admite a representação (art. 1.852)" ${ }^{86}$ A sucessão decorrente dos ascendentes possui dois princípios norteadores, quais sejam, “a) o grau mais próximo exclui o mais remoto, sem distinção de linhas; b) havendo igualdade em grau e diversidade em linha, os ascendentes da linha paterna herdam a metade, cabendo a outra aos da linha materna". ${ }^{87}$

Também, nesse caso, haverá a possibilidade da concorrência do cônjuge sobrevivente com os ascendentes, hipótese essa trazida pelo artigo 1.836 do Código Civil de 2002. O cônjuge supérstite concorrerá com os ascendentes, independente do regime de bens adotado no casamento. ${ }^{88}$

Na concorrência do cônjuge sobrevivente com os ascendentes, conforme preceitua o artigo $1.837^{89}$ do

85 LAGRASTA NETO, Caetano. Direito de família: novas tendências e julgamentos emblemáticos. São Paulo: Atlas, 2011, p. 122.

86 LEITE, Eduardo de Oliveira. Direito civil aplicado: direito das sucessões. 2. ed. v. 6. São Paulo: Revista dos Tribunais, 2012, p. 120.

87 "Se apenas um está vivo, recebe a totalidade da herança, ainda que estejam vivos os pais do genitor falecido (avós do de cujus), pois na linha ascendente, como mencionado, não há direito de representação. Se ambos faltarem, herdarão os avós da linha paterna e materna; na falta deles, os bisavós, e assim sucessivamente. [...] Se concorrerem à herança avós de linhas diversas (paterna e materna), em número de quatro, dividi-se a herança em partes iguais entre as duas linhas. Se são três os avós (igualdade de graus), sendo dois paternos e um materno (diversidade em linha), reparte-se a herança entre as duas linhas meio a meio, cabendo metade para os dois avós paternos (de uma linha), e metade para o único avô materno (da outra linha)” (GONÇALVES, Carlos Roberto. Direito civil brasileiro: direito das sucessões. 4. ed. v. 7. São Paulo: Saraiva, 2010, p. 178-179.)

88 GONÇALVES, Carlos Roberto. Direito civil brasileiro: direito das sucessões. 4. ed. v. 7. São Paulo: Saraiva, 2010, p. 180.

89 Artigo 1.837 do Código Civil de 2002: “Concorrendo com ascendente em primeiro grau, ao cônjuge tocará um terço da herança; caber-lhe-á a metade desta se houver um só ascendente, ou se maior for aquele grau.” 
Código Civil de 2002, o mesmo poderá receber quotas variáveis. Assim, se o cônjuge concorrer com os ascendentes em primeiro grau - pais - receberá 1/3 da herança, no entanto, se concorrer com apenas um dos pais do de cujus, ou se maior for aquele grau, receberá metade da herança. Seguindo esse pensamento, nos valemos dos ensinamentos de Silvio de Salso Venosa, que afirma que

[...] de acordo com o atual código, a herança será dividida em três partes iguais se o cônjuge sobrevivente concorrer com o sogro e sogra. Se houver apenas o sogro ou a sogra vivo ou se os herdeiros ascendentes forem de grau mais distante, o cônjuge receberá sempre a metade da herança. [...] Advirta-se que a situação não se aplica à união estável, que possui regra própria. [...] Assim, se presente uma única linha (avós paternos, por exemplo), a herança será conferida e ela, assegurando-se a parcela do cônjuge sobrevivente. Havendo, por exemplo, um avô paterno e dois maternos, deduzida a metade do cônjuge, o restante da herança é dividida novamente ao meio, para o avô paterno e para os dois outros avós. A mesma regra será seguida se existirem ascendentes mais distantes. A divisão por linha só se opera uma única vez..$^{90}$

\section{G) Da sucessão do cônjuge: inexistência de herdeiros necessários}

O cônjuge sobrevivente casado ou separado de fato há menos de dois anos receberá a totalidade da herança caso não haja descendentes ou ascendentes, uma vez que "ocupa sozinho a terceira classe da ordem da sucessão hereditária”. ${ }^{91}$

\section{H) Do direito real de habitação do cônjuge sobrevivente}

O cônjuge sobrevivente, conforme preceitua o Código Civil, em seu artigo $1.831^{92}$, terá assegurado, independente do regime de bens eleito no casamento, o direito real de habitação $0^{93}$, no que tange à moradia fami-

90 VENOSA, Sílvio de Salso. Direito civil: direito das sucessões. 8. ed. v. 7. São Paulo: Atlas, 2008, p. 123.

91 GONÇALVES, Carlos Roberto. Direito civil brasileiro: direito das sucessões. 4. ed. v. 7. São Paulo: Saraiva, 2010, p. 180.

92 Artigo 1.831 do Código Civil de 2002: “Ao cônjuge sobrevivente, qualquer que seja o regime de bens, será assegurado, sem prejuízo da participação que lhe caiba na herança, o direito real de habitação relativamente ao imóvel destinado à residência da família, desde que seja o único daquela natureza a inventariar”.

93 Direito civil. Sucessões. Direito real de habitação do cônjuge supérstite. Evolução legislativa. Situação jurídica mais vantajosa para o companheiro que para o cônjuge. 
liar e desde que esse bem seja o único dessa natureza a inventariar. Assim, fica resguardado o interesse do cônjuge supérstite.

\section{CONSIDERAÇÕES FINAIS}

Diante de todo o exposto, podemos concluir que o direito sucessório, nascido na Antiguidade, ainda é ob- jeto de muitas polêmicas e posicionamentos diversos para uma mesma situação jurídica. Assim, o conjunto de normas e princípios que regem a transmissão de direitos e obrigações deixados pelo de cujus precisa, ainda, ser muito debatido nos bancos acadêmicos para que não haja injustiça nas decisões a serem tomadas, levando-se sempre em conta o princípio da proteção à família.

\section{REFERÊNCIAS}

BEVILÁQUA, Clóvis. Direito das sucessões. Rio de Janeiro: Freitas Bastos, 1945.

BRASIL. Código Civil e Constituição Federal. 64. ed. São Paulo: Editora Saraiva, 2013.

CAHALI, Francisco José; HIRONAKA, Giselda Maria Fernandes Novaes.
Direito das sucessões. 4. ed. São Paulo: Revista dos Tribunais, 2012. CATEB, Salomão de Araújo. Direito das sucessões. 4. ed. São Paulo: Atlas, 2007.

DIAS, Maria Berenice. Manual das sucessões. São Paulo: Revista dos Tribunais, 2011.

Equiparação da união estável.1. O CC/1916, com a redação que lhe foi dada pelo Estatuto da Mulher Casada, conferia ao cônjuge sobrevivente direito real de habitação sobre o imóvel destinado à residência da família, desde que casado sob o regime da comunhão universal de bens. 2. A Lei 9.278/1996 conferiu direito equivalente aos companheiros e o CC/2002 abandonou a postura restritiva do anterior, estendendo o benefício a todos os cônjuges sobreviventes, independentemente do regime de bens do casamento. 3. A CF (art. 226, § 3. ${ }^{\circ}$ ), ao incumbir o legislador de criar uma moldura normativa isonômica entre a união estável e o casamento, conduz também o intérprete da norma a concluir pela derrogação parcial do § 2. ${ }^{\circ}$ do art. 1.611 do CC/1916, de modo a equiparar a situação do cônjuge e do companheiro no que respeita ao direito real de habitação, em antecipação ao que foi finalmente reconhecido pelo CC/2002.4. Recurso especial improvido. Superior Tribunal de Justiça. REsp 821.660. Julgado em: 14/6/2011. Decisão unânime. Rel. Sidnei Beneti. 
DIAS, Maria Berenice. Manual de direito das famílias. São Paulo: Revista dos Tribunais, 2012.

DINIZ, Maria Helena. Curso de direito civil brasileiro. 22. ed. v. 6. São Paulo: Saraiva, 2008.

FACHIN, Luiz Edson. Direito de família: elementos críticos à luz do novo Código Civil brasileiro. 2. ed. Rio de Janeiro: Renovar, 2003.

GAGLIANO, Pablo Stolze; PAMPLONA FILHO, Rodolfo. Novo curso de direito civil. 2. ed. v. 6. Sâo Paulo: Saraiva,2012.

GONÇALVES, Carlos Roberto. Direito civil brasileiro: direito das sucessões. 4. ed. v. 7. São Paulo: Saraiva, 2010.

LAGRASTA NETO, Caetano. Direito de família: novas tendências e julgamentos emblemáticos. São Paulo: Atlas, 2011.

LEITE, Eduardo de Oliveira. Direito civil aplicado: direito das sucessões. 2. ed. v. 6. São Paulo: Revista dos Tribunais, 2012.

MONTEIRO, Washington de Barros. Curso de direito civil. 30. ed. v. 6. São Paulo: Saraiva, 1995.

MONTEIRO, Washington de Barros. Curso de direito civil: direito das sucessões. 35. ed. v. 6. São Paulo: Saraiva, 2003.

NERY JÚNIOR, Nelson; ANDRADE NERY, Rosa Maria. Código Civil comentado. 8. ed. São Paulo: Revista dos Tribunais, 2011.

NORONHA, Carlos Silveira. Reflexões doutrinárias acerca do direi- to das sucessões. In: NORONHA, Carlos Silveira (Org.). As novas perspectivas do direito das sucessões em tempos de modernidade e pós-modernidade. Porto Alegre: Sulina, 2011.

OLIVEIRA, Euclides Benedito de. Direito de herança: a nova ordem da sucessão. São Paulo: Saraiva, 2005.

PEREIRA, Caio Mário da Silva. Instituições de direito civil. 12. ed. v. 6. Rio de Janeiro: Forense, 2005.

PONTES DE MIRANDA. Tratado de direito privado, Parte Especial, TOMO LV. Direito das sucessões: Sucessão em geral. Sucessão legítima. 3. ed. § 5.614, capítulo 2. Rio de Janeiro: Borsoi, 1972.

SANTOS. Luiz Felipe Brasil. A sucessão dos cônjuges no novo Código Civil. IBDFAM. Publicado em 31/03/2003. Disponível em: http://www.ibdfam.org. $\mathrm{br} /$ ?artigos\&artigo $=85$. Acessado em: 27 maio 2012.

VELOSO, Zeno. Direito hereditário do cônjuge e do companheiro. São Paulo: Saraiva, 2010.

VELOSO, Zeno. Novo Código Civil comentado. Coordenação de Ricardo Fiuza. São Paulo: Saraiva, 2002.

VENOSA, Sílvio de Salso. Direito civil: direito das sucessões. 8. ed. v. 7. São Paulo: Atlas, 2008.

WALD, Arnold. Direito civil: direito das sucessões. v. 6. 15. ed. São Paulo: Saraiva, 2012. 